\title{
OXIDATIVE STRESS AND CARCINOGENESIS: POTENTIAL OF PHYTOCHEMICALS IN BREAST CANCER THERAPY USING MCF-7
}

\author{
Gilead Ebiegberi Forcados ${ }^{1,2,3}$, Peace Mabeta ${ }^{2}$, Dorcas Bolanle James ${ }^{3}$, Abdullahi Balarabe \\ Sallau $^{3}$, Aliyu Muhammad ${ }^{3}$ \\ Biochemistry Division, National Veterinary Research Institute, Vom. Nigeria ${ }^{1}$ \\ Department of Anatomy and Physiology, Faculty of Veterinary Sciences, University of Pretoria ${ }^{2}$ \\ Department of Biochemistry, Ahmadu Bello University, Zaria. Nigeria ${ }^{3}$
}

\begin{abstract}
Despite intensive research in the field of breast cancer, the disease remains a burden in both developed and developing countries, despite the use of chemotherapy and other synthetic drugs. Reactive oxygen species mediated oxidative stress is known to play a role in breast cancer pathogenesis via genetic and epigenetic modifications, resulting in uncontrolled cell proliferation. Phytochemicals could provide leads for the development of alternative therapeutic agents due to their antioxidant activity, as well as apoptosis inducing effect on cancer cells. The MCF-7 cell line, an ER-positive cell line, has been used to provide insights into the potential of phytochemicals as anti-cancer agents. However, most of such in vitro studies do not continue with further studies in ER-positive in vivo breast cancer models, or fail to examine the possible biochemical mechanisms of phytochemical based amelioration. This review examines oxidative stress mediated carcinogenesis and the potential of phytochemicals as anti-cancer agents.
\end{abstract}

KEY WORDS: Oxidative stress, carcinogenesis, phytochemicals, MCF-7, breast cancer

\section{INTRODUCTION}

Breast cancer is a frequently diagnosed neoplastic disease in women around menopause, in both developed and developing countries, and among the leading cause of cancer deaths in women [1]. It is reportedly the second most diagnosed cancer worldwide, accounting for 522,000 deaths in 2012 alone [2]. In South Africa, breast cancer is the most common malignancy among women [3]. In Nigeria, out of a reported 4521 documented cancer cases at the Ibadan Population Based Cancer Registry and the Abuja Population Based Cancer Registry covering only a 2 year period of 2009 and 2010, breast cancer was the most common [4]. The economic burden of breast 
cancer in the U.S including medical bills and productivity loss from morbidity is estimated at $\$ 5.49$ billion per annum [5].

Cancer is characterized by an abnormal growth of cells, caused by multiple changes in genetic material and gene expression, ultimately resulting in a population of rapidly dividing cells that could metastasize to distant sites, causing significant morbidity and sometimes, death of the host. Breast tissue is particularly sensitive to developing cancer for several reasons. The female hormone estrogen stimulates breast cell division in normal females [6]. This continuous division can increase the risk of making damage to DNA permanent in breast cells. Furthermore, breast cells are not fully matured in girls and young women who have not had their first full-term pregnancy. In developing mammary glands, environmental carcinogens bind to DNA of breast cells more strongly, and these breast cells are less efficient at repairing DNA damage compared to cells in developed or fully mature mammary glands [7].

At present, there are numerous experimental reports on the different biological activities of phytochemicals against breast cancer and carcinogenesis using MCF-7 cell lines. However, a comprehensive review that collates experimental evidence, critically appraises the achievements documented so far as well as provides future research directions in the area of oxidative stress mediated-carcinogenesis related to phytochemical antioxidants in breast cancer therapy is lacking. Therefore, this review examines the link between oxidative stress and breast cancer at the cellular and molecular level, while also providing a critical appraisal on available experimental data on the potential of phytochemicals in breast cancer therapy.

\section{OXIDATIVE STRESS AND CARCINOGENESIS}

Oxidative stress is defined as a physiological state in which the generation of reactive oxygen species (ROS) overwhelms the antioxidant metabolites, resulting in an imbalance, in favor of the amount of free radicals [8]. Reactive oxygen species and free radicals are products of normal cellular metabolism and play important roles in cell signaling pathways [9]. Most reactive species are generated in the mitochondria, especially when electrons leak to oxygen $\left(\mathrm{O}_{2}\right)$ during ATP generation, resulting in the formation of the superoxide anion $\left(\mathrm{O}_{2}{ }^{-}\right)$. The superoxide anion can further react with other molecules, resulting in the generation of other reactive species like hydrogen peroxide $\left(\mathrm{H}_{2} \mathrm{O}_{2}\right)$, hydroxyl radical $\left(\mathrm{OH}^{\circ}\right)$, and organic peroxides [10]. 
The major deleterious effects of ROS in mammalian cells are mediated by the hydroxyl radical $(\mathrm{OH} \cdot)$. It has a very unstable electron structure, easily reacting with cellular components, and is mainly produced via the Fenton reaction when hydrogen peroxide reacts with $\mathrm{Fe}^{2+}$ during hypoxic conditions, like prolonged exercise and disease conditions like diabetes. The mitochondrial respiratory chain also produces nitric oxide (NO), which can generate other reactive nitrogen species (RNS) [11].

Both ROS and RNS can react with cellular macromolecules like lipids, inducing lipid peroxidation that causes the formation of reactive intermediates: malondialdehyde and 4hydroxynonenal [12]. MDA is mutagenic in bacterial and mammalian cells and carcinogenic in rats. The major effect of lipid peroxidation by ROS is seen in the integrity of cell membranes. The polyunsaturated fatty acid residues of phospholipids, are extremely sensitive to oxidation. Oxidation of membrane phospholipids by ROS causes alterations to the integrity of the membrane and normal functioning of the cell [13].

A cell with altered mitochondrial membrane integrity is prone to apoptosis, as changes to the inner mitochondrial membrane integrity results in opening of the mitochondrial permeability transition (MPT) pore, loss of the mitochondrial transmembrane potential and release of cytochrome $c$ which is normally a sequestered intermembrane pro-apoptotic protein [14]. The released cytochrome c binds and activates Apaf-1 and downstream procaspase- 9 , forming an apoptosome, thereby activating the intrinsic caspase dependent apoptotic pathway [15].

Studies examining the oxidation of proteins by ROS have shown that amino acids, simple peptides and proteins exposed to conditions where hydroxyl radicals or a mixture of hydroxyl/superoxide radicals are present are prone to damage and altered function [16]. The side chains of amino acid residues of proteins, rich in cysteine and methionine are particularly susceptible to oxidation by the action of ROS. The oxidation of cysteine residues by ROS can lead to formation of disulphide bonds between protein thiol groups [17]. The concentration of carbonyl groups, generated as products of protein oxidation by ROS is a good measure of ROSmediated protein oxidation. Protein carbonyls represent an irreversible form of protein modification [18].

During severe oxidative stress seen in certain disease conditions, increased protein oxidation and consequently impaired proteolytic systems results in an accumulation of oxidized proteins and 
finally to the formation of non-degradable protein aggregates, altering cellular homeostasis functions seen in diseases like cancer [17]. Advanced glycation end products, which are reported to be mutagenic, are formed by a reaction between the free amino group of proteins and carbohydrates [19]. Glycation causes a modification of the structural properties of proteins such as albumin and haemoglobin leading to inflammation and further exacerbating oxidative stress. Glycated proteins form aggregations, which are insoluble and resistant to degradation, and also interact with signaling pathways (MAPK, NF-kB) implicated in carcinogenesis [20].

The hydroxyl radical is reported to react with all components of the DNA molecule, damaging both the purine and pyrimidine bases and also the deoxyribose backbone. When such oxidative damage to DNA occurs, molecules like $8-\mathrm{OH}$ deoxyguanosine $(8-\mathrm{OHdG})$ are generated which increase the risk of mutagenesis. $8-\mathrm{OHdG}$ is a widely used indicator of free radical attack on DNA. 8-OHdG is strongly implicated in the progression of carcinogenesis. In breast carcinomas, $8-\mathrm{OHdG}$ is reportedly increased 8 - to 17 -fold in breast primary tumors compared with nonmalignant breast tissue [21]. 8-OHdG can induce GC $\rightarrow$ TA transversion mutations particularly during DNA replication, with a potential for mutagenicity if the oxidative lesions are not repaired, resulting in cancer initiation [22]. DNA adducts formation in the coding region of tumor suppressor proteins like TP53, can cause altered function, resulting in cancer promotion, progression and metastasis [23].

Thus, there is interplay between oxidative stress and carcinogenesis, as oxidative stress results in oxidation of lipids to form MDA and 4-HNE which have been found to be mutagenic, playing a possible role in cancer initiation. Oxidative stress can also result in DNA oxidation, forming DNA adducts, resulting in altered transcription, translation and consequently protein function, which is implicated in tumor promotion and progression. Oxidative stress can also result in oxidation of cysteine residues of antioxidants like glutathione and thioredoxin, further contributing to redox imbalance in the cells, resulting in activation of specific transcription factors implicated in cell proliferation that are observed in cancer progression. Oxidative stress can also cause oxidation of side chain amino acids of proteins resulting in altered function, especially of proto-oncogenes. We can therefore suggest that, at each stage of initiation, promotion, progression and metastasis, oxidative stress can play a role. 


\section{TRANSCRIPTION FACTORS AND PROTEINS IMPLICATED IN OXIDATIVE STRESS MEDIATED CARCINOGENESIS}

\section{Activator protein-1}

Activator pprotein-1 (AP-1) is a collection of dimeric basic region-leucine zipper (bZIP) proteins that belong to the Jun (c-Jun, JunB, JunD), Fos (FosB, Fra-1, Fra-2), Maf, and ATF subfamilies, all of which can bind the tumour-promoting agent (TPA) or cAMP response elements. c-Jun, a potent transcriptional regulator, often forms stable heterodimers with Jun proteins, which aid the binding of Jun to DNA [24]. AP-1 activity is induced in response to certain metals in the presence of $\mathrm{H}_{2} \mathrm{O}_{2}$ as well as by several cytokines and other physical and chemical stresses. AP-1 plays an important role in cell cycle progression, because it is a transcription factor for cyclin D1, which is required for progression through the G1 phase on the cell cycle [25]. Since the transition from $G_{0}$ to $G_{1}$ is the only phase of the cell cycle that is regulated by redox-dependent signaling pathways, expression of cyclin D1 represents a primary regulatory point in the induction of cell growth. Aberrant expression and activity of Ap-1 during oxidative stress is implicated in carcinogenesis [26].

A study examined the expression of AP-1 members of the JUN and FOS protein families at the mRNA level in primary breast tumors and compared this to adjacent non-tumor tissues to determine any correlation with clinicopathological parameters. The results revealed significant differences in the expression of AP-1 family members between tumor and adjacent non-tumor tissues, implicating altered AP-1 activity in breast carcinogenesis [27].

\section{Nuclear factor-kappa beta $(\mathrm{NF}-\boldsymbol{\kappa} B)$}

Literature reports indicate that ROS are able to activate the Nuclear factor kappa beta (NF-kB) transcription factor [28]. NF-kB is an inducible and ubiquitously expressed transcription factor for some genes responsible for cell survival, differentiation, inflammation, growth and angiogenesis [29]. In the unstimulated state, NF-kB is sequestered in the cytoplasm because of an interaction with inhibitory protein IkB [30]. However, in a response to certain extracellular stimuli, the inhibitory bond between IkB and NF-kB is dissociated, allowing the translocation of NF-kB into the nucleus, where it binds $k B$ regulatory elements [31].

Analysis of tumor cells from blood neoplasms and cell lines from different cancers, showed

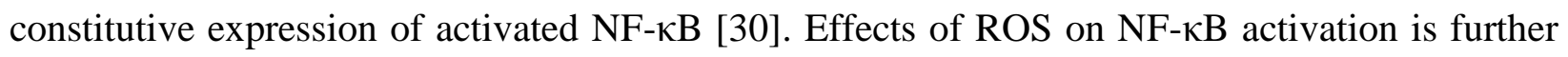
supported by experiments which demonstrated that activation of $\mathrm{NF}-\kappa \mathrm{B}$ can be blocked by 
antioxidants, such as L-cysteine, $\mathrm{N}$-acetylcysteine, thiols, green tea, polyphenols, and vitamin $\mathrm{E}$, although this might be not very specific because antioxidants have multiple targets [28].

Thus, NF-kB activation promotes cell proliferation, whereas the inhibition of NF-kB activation blocks cell proliferation. $\mathrm{H}_{2} \mathrm{O}_{2}$ is able to degrade $\mathrm{I} \kappa \mathrm{B} \alpha$, the inhibitory subunit of $\mathrm{NF}-\kappa \mathrm{B}$ by reacting with its cysteine residues, resulting in activation of NF-kB activity and downstream increased pro-inflammatory protein expression implicated in carcinogenesis [32]. Reactive oxygen species have also been implicated as second messengers involved in the activation of NF-kB through upstream activation of tumour necrosis factor (TNF) pathway, which are associated with carcinogenesis [32].

It has been shown that constitutive NF- $\kappa \mathrm{B}$ activation is found in estrogen receptor-negative (ERnegative) and ErbB2-positive tumors, with significant effects on the initiation and progression of breast cancer [33]. Inhibition of NF-kB reportedly increased tumor latency and decreased tumor burden in an in vivo breast cancer model [34]. Thus, there is a critical link between NF-KB and cell survival, differentiation, and proliferation in breast carcinogenesis, suggesting NF-kB as a novel target for breast cancer drug development [35].

\section{p53}

The nuclear factor p53, sometimes referred to as "guardian of the genome", plays a key role in protecting a cell from tumourigenesis [36]. Due to its remarkable ability to halt the cell cycle or initiate apoptosis when a cell is damaged, it is classified as a "tumour suppressor". In more than half of human cancers, mutations in p53 leading to its inactivation has been observed [37]. P53 is activated by UV radiation, hypoxia, gamma-radiation, nucleotide deprivation among others. Several cysteine residues in the central domain of the protein are critical for p53 binding to the specific DNA sequence [38].

Studies show that under normal/low cellular stress, low concentrations of p53 induce the expression of antioxidant genes, whereas in severe cellular stress, high concentrations of p53 promote the expression of genes that contribute to ROS formation and p53-mediated apoptosis, protecting cells from oxidative DNA damage [39]. However during oxidative stress conditions, abberant p53 activity contributes to carcinogenesis, as cells which are supposed to be targeted for apoptosis survive [39]. 
Although the frequency of mutation in p53 is relatively lower in breast cancer than in other solid tumors, p53 mutation is associated with more aggressive breast carcinogenesis [40]. Genetic and epigenetic alterations have been identified in regulators of p53 activity and in some downstream transcriptional targets of p53 in breast cancers that express wild-type p53. Mutations in p53 is reported to occur in a high proportion of individuals with the $\mathrm{Li}$-Fraumeni cancer susceptibility syndrome, which confers an increased risk of breast cancer, implicating p53 inactivation in mammary carcinogenesis [23].

\section{Mitogen activated protein kinases (JNK, p38)}

The mitogen activated protein kinases are a group of proteins that play a vital role in cell signaling. Mitogen activated protein kinases (MAPK) are known to be activated in response to growth factors, inflammatory cytokines and cellular stress signals, which are conditions often observed during oxidative stress [41]. Current research has examined possible mechanisms by which reactive oxygen species (ROS), alter the activity and function of these essential kinases. The JNKs and p38 MAPK are collectively referred to as stress activated protein kinases (SAPKs) due to their activation by cellular stress factors. JNKs are ubiquitously expressed, and the JNK stress pathways participate in many different intracellular signaling pathways [42]. JNK has been reported to activate transcription factors in addition to c-Jun, such as Elk-1, p53, and c-Myc as well as nontranscription factors such as Bcl-2 and Bcl-xL [41].

The effect of c-Jun on p53 protein levels is evidenced by the effect of c-Jun on p53 mRNA expression: c-Jun binds to and represses the p53 promoter, and overexpression of c-Jun represses p53 mRNA levels. p53 is a transcptional activator of p21, which regulates cell cycle progression via its interaction with mdm2 [37]. Thus c-Jun when activated by ROS during oxidative stress in the ERK-MAPK pathway, can act as an oncogene (when mutated or expressed in a deregulated way).

MAPKs can have diverse outcomes, depending on the nature, intensity and duration of the stimuli, which range from the induction of apoptosis to increased survival and altered proliferation observed in cancers [42]. JNK and p38 have been shown to play important roles in mammary gland development [43]. Studies have shown that inactivation of p38 signaling and aberrant regulation of JNK foster breast cancer progression [44] 


\section{Estrogen receptor}

It has been shown that longer duration to estrogen exposure correlates with an increased risk for breast cancer [45]. The breast tissue is particularly dependent on circulating estrogens since experiments have revealed no breast development in aromatase-deficient women and estrogen therapy of these patients leads to normal pre- and postpubertal breast development. Estrogen effects are exerted through the estrogen receptor alpha and beta [46].

Estrogen receptors act mainly by regulating the expression of certain target genes whose promoters contain specific sequences called estrogen-responsive element (ERE). After EREbinding of ligand-bound ER dimers, modulation of transcription occurs through interaction with coactivators or corepressors, resulting in the recruitment of transcriptional machinery, modulation of chromatine structure, and regulation of ER target-gene expression [47]. Chronic oxidative stress has been shown to affect the development and aggressive growth of estrogen receptor in ER-positive breast cancer, and estrogen-independent growth is one of the features of the aggressive subtype of breast cancer [48].

Altered estrogen receptor (ER) expression is observed in about $75 \%$ of human breast cancers [49]. Under physiological conditions, ligand-bound ER activates gene expression through direct binding to specific DNA response elements or with co-activators at DNA response elements, through protein-protein interactions with other transcription factors like activation protein 1 (AP1) and nuclear factor-kappa beta $(\mathrm{NF}-\kappa \mathrm{B})$. Such ER activity results in the transcription and activation of downstream proteins required for breast cell proliferation [50]. During oxidative stress, ER can also be activated without ligand binding through signaling events by the serine/threonine kinases: ERKs, JNK and p38 of the MAPK pathway, which are deregulated in breast cancer [51].

\section{BRCA 1 and 2}

Research conducted so far, has led to the identification of genes whose abnormal function is associated with an increased risk of occurrence of malignant breast cancer. BRCA1 and BRCA2 (breast cancer susceptibility gene 1 and 2) which are the most prominent, are tumor suppressor genes in a normal cell [52]. However, changes in the coding sequence of the genes may lead to the development of the hereditary syndrome, called HBC-SS (Hereditary Breast Cancer Site 
Specific) syndrome, which manifests in the form of breast cancer. Mutations in BRCAl or $B R C A 2$ genes are associated with an increased risk of occurrence of breast cancer in about $65 \%$ of mutation carriers [52]. BRCA1 and BRCA2 are responsible for DNA repair, and mutations to these genes are associated with loss of DNA repair function [53]. Genome stability is compromised when cells are exposed to oxidative stress. Thus, oxidative stress mediated damage to BRCA 1 and 2 DNA, can cause altered function of this protein as seen in breast cancer [53].

Recent discoveries point to synergistic signaling between BRCA1 and ER in regulating mammary epithelial cell proliferation and differentiation. We have earlier shown the interaction that exists between ER, AP-1 and MAPK. It is known that BRCA1 can inhibit-ER signaling by complexing with ER directly, ensuring quality of replicated genome DNA when the cells experience proliferation under mitogenic effect of ER. In BRCA1 deficiency or absence, this balance is altered, causing cells to accumulate genomic mutations, contributing to the oncogenic transformation of mammary epithelial cells [54]. Also, absence of BRCA1 reduces the ability of cells to deal with oxidative stress from the estrogen metabolism pathway, causing higher exposure to oxidative damage and accelerating tumorigenesis in breast tissue [55].

\section{ROLE OF ANTIOXIDANTS IN CHEMOPREVENTION}

Certain antioxidants and polyphenolic compounds have been reported to exert anti-proliferative effects on breast cancer cells [56]. The activity of inflammatory cytokines (Interleukin 6, Tumor necrosis factor- $\alpha$ ), transcription factors (Nuclear factor-kB, Activator protein-1), and geneproducts linked with cell survival and proliferation, can be modified by such polyphenolic compounds [57].

The different parts of plants have been reported to have antioxidant and anti-cancer properties [58]. Antioxidants like glutathione and thioredoxin, can directly scavenge reactive oxygen species, by donating their hydrogen atoms to the reactive species, converting them to less radical forms. Some phytocompounds have also been reported to activate the Nrf-2 transcription factor, enhancing the upregulation and expression of antioxidant enzymes [59].

Antioxidants can also induce apoptosis in cancer cells [56], by binding to transmembrane lipids, causing loss of the mitochondrial transmembrane potential and release of cytochrome $c$, thus activating the intrinsic caspase dependent apoptotic pathway [15]. Figure 1 below illustrates the 
potential role of phytochemical antioxidants in different oxidative stress mediated carcinogenesis pathway
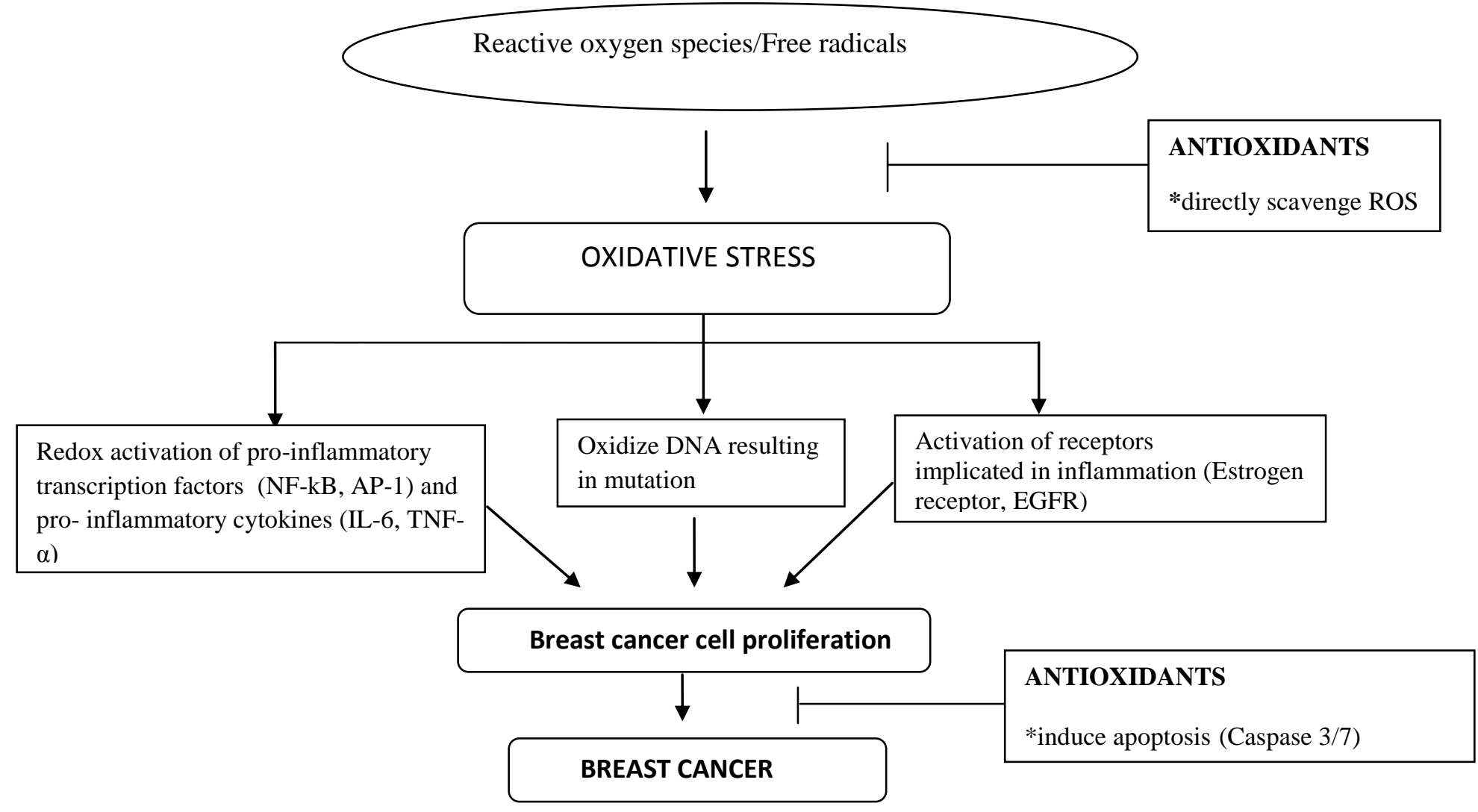

Figure 1: Role of antioxidants in chemoprevention

- Reactive oxygen species mediated oxidative stress plays a role in carcinogenesis by

(i) altering the redox state of cells, thereby activating pro-inflammatory transcription factors (NF-kB, AP-1) and pro- inflammatory cytokines (IL-6, TNF- $\alpha$ )

(ii) oxidizing DNA and causing changes in the coding region of key regulatory proteins

(iii) oxidation of cysteine residues in key receptors which get auto activated without ligand binding - processes which favor cell proliferation.

Antioxidants derived from phytochemicals can play a role in chemoprevention by quenching reactive species, thus preventing oxidative stress, and can also induce apoptosis in cancer cells by enhancing effector caspase activity. 
Thus, upstream or downstream of the oxidative stress mediated cancer pathway, antioxidants play a beneficial role by inhibiting oxidative stress or by inducing death in cancer cells, as illustrated in Figure 1.

\section{MCF-7 - A MODEL FOR ANTI-CANCER STUDIES}

MCF-7 is the acronym of Michigan Cancer Foundation-7, a cell line first isolated in 1970 from the pleural effusion of a patient with metastatic breast cancer. It is the most studied human breast cancer cell line in the world, relevant for in vitro breast cancer research because the cells retain certain ideal characteristics particular to the mammary epithelium, which include ability to process estrogen in the form of estradiol, via estrogen receptors in the cytoplasm [60]. Results from studies carried out using this cell line have had a fundamental impact on breast cancer research and patient outcomes [60]. A number of studies have been conducted to examine the inhibitory effects of compounds on MCF-7 cell proliferation [61].

The use of cell lines in cancer research is advantageous in that they offer an infinite supply of a relatively homogeneous cell population, capable of speedy self-replication in standard cell culture medium, facilitating replication studies using both synthetic and natural test drugs [62]. A major contribution of the MCF-7 cell line to breast cancer research has been in the study of estrogen receptor (ER) alpha, because this unique cell line expresses significant levels of ER mimicking the majority of invasive ER-positive human breast cancer patients [63].

It is important to note that concerns have been raised about how representative research carried out using cell lines is of human breast cancer [64]. However, it is unquestionable that, breast cancer cell lines are important experimental tools for research, both basic and applied. One example that backs this view is the research on MCF-7 cells which showed that anti-estrogens regulated the growth of tamoxifen-stimulated cells. This work resulted in the development of fulvestrant $\left(\right.$ Faslodex $^{\circledR}$, AstraZeneca Pharmaceutical LP, Wilmington, DE, USA), a selective ER downregulator that is now recommended for the treatment of recurrent ER-positive, metastatic breast cancer in the postmenopausal patients [65].

\section{ANTI-CANCER EFFECTS OF PHYTOCHEMICALS USING MCF-7 CELL LINE}

The cytotoxicity of methanol and dichloromethane extracts of Piper cubeba seeds was evaluated against MCF-7 cell lines [66]. Using the MTT assay, it was observed that a chromatographic 
fraction of the plant extract exhibited cytotoxic activity against breast cancer cells and normal epithelial breast cells, suggesting non-specific cytotoxicity [66].

Another study examined the anti-cancer effects and mechanisms of action of Mikania cordata plant extract on MCF-7 cell line, comparing the cytotoxicity of the extract to normal J774A.1 murine macrophage cells [67]. The results showed the limited potential of the extract as an anticancer agent as it inhibited proliferation of both normal and cancer cells, indicating non-specific cytotoxicity.

The antioxidant potency and anti-cancer effects of extract and fractions of Nardostachys jatamansi DC were examined using MCF-7 cell line [68]. The results showed that antioxidant activity of the fractions correlated with phenolic content and anti-proliferative activity, providing further evidence for the role of antioxidants as possible anti-cancer agents. The most potent fraction caused G0/G1 phase arrest in MDA-MB-231 cells [68], showing great promise for further studies to possibly obtain an anti-cancer agent.

Centratherum anthelminticum (L.), a medicinal herb in Indian sub-continent, was examined for its anticancer activity on the MCF-7 cell line. The report suggested that a chloroform fraction of the plant seeds inhibited growth of MCF-7 human breast cancer cells by inducing apoptosis, evident by cell size shrinkage, deformed cytoskeletal structure and DNA fragmentation. Bioassay-guided fractionation employing HPLC isolation, NMR and LC-MS analysis, lead to the identification of vernodalin as the active cytotoxic agent. MCF-7 cells treated with vernodalin showed downregulation of anti-apoptotic molecules (Bcl-2, Bcl-xL), reduction of mitochondrial membrane potential (MMP) and release of cytochrome c. The release of cytochrome c from mitochondria to cytosol triggered activation of caspase cascade, and eventual cell death [69]. The results show great promise for the use of vernodalin, but requires further studies to examine what results would be obtained from in vivo experiments using vernodalin in breast cancer induced animal model.

Cytotoxic effects of dichloromethane fractions of Scrophularia oxysepala extract on the MCF-7 breast cancer cell line have been studied using trypan blue dye exclusion and MTT assays. The ability of the extract to induce apoptosis was determined using TUNEL assay and DNA fragmentation analysis. Quantitative Real-Time PCR was used to observe changes in Caspase-3, 
Caspase-9, and Bcl-2 genes expression. The results showed inhibition of growth and viability, increased expression of Caspase-3and Caspase-9 mRNA, induction of apoptosis, in MCF-7 cells treated with dichloromethane fractions, showing great promise for use in in vivo experiments [70].

The effects of curcumin, a phytochemical obtained from the plant Curcuma longa has been examined in MCF-7 cells. MTT assay, was used to evaluate cell viability, western blot was used for protein expression, while flow cytometry, acridine orange staining and transmission electron microscopy were used to detect apoptosis in the cells. Curcumin caused growth inhibition and induced apoptosis. Expression of the anti-apoptotic protein Bcl-2 decreased while expression of the pro-apoptotic protein Bax increased, explaining possible mechanisms by which curcumin exerts anti-cancer effects [71]

Flavopiridol is an alkaloid derived from the stem bark of Dysoxylum binectariferum which has been found to exhibit cytotoxity on MCF-7 cancer cell line, by inhibiting cyclin-dependent kinases that are responsible for cell cycle control [72]. A study employed metabolomics approach to investigate the antiproliferative effects of flavopiridol on MCF-7 breast cancer cells. The results showed cell cycle inhibition at $\mathrm{G}_{1}$ stage reduced glutathione and phosphatidylcholine levels and increased level of their oxidized products, as well as decreased mitochondrial membrane potential, resulting in apoptosis, explaining possible antitumor mechanism of flavopiridol as a potential anti-breast cancer drug [73].

Lycopene, a rich antioxidant compound, a major carotenoid present in tomatoes (Solanum lycopersicum), has been evaluated for anti-proliferative effects on MCF-7 cells. Lycopene is a 40-carbon aliphatic chain containing thirteen trans- double bonds, eleven of which are conjugated [72]. Lycopene treatment for seven consecutive days induced strong and sustained activation of the ERK1/2 with downstream cyclin D1 suppression and p21 upregulation [74].

Another study examined the anti-cancer potential of resveratrol on phosphofructokinase activity [75]. Resveratrol is a phenolic compound found in grapes (Vitis vinifera L.; Vitaceae) and some other fruits. Altered glucose metabolism is a characteristic of cancer cells for which the enzyme phosphofructokinase-1 is implicated [76]. Administration of resveratrol caused a reduction of 
cell viability, decreased phosphofructokinase-1 activity and decreased glucose metabolism in the MCF-7 cells [75], explaining possible mechanisms justifying its use as an anti-cancer agent.

These selected studies summarized in Table 1 below, shows the potential of phytochemicals in obtaining therapeutic agents for use by breast cancer patients

Table 1

\begin{tabular}{|c|c|c|c|c|}
\hline Plant & $\begin{array}{l}\text { Phytochemical } \\
\text { isolated }\end{array}$ & $\begin{array}{l}\text { Antioxidant } \\
\text { property }\end{array}$ & $\begin{array}{l}\text { In vitro assays } \\
\text { used on MCF-7 } \\
\text { cell line }\end{array}$ & Description of effects \\
\hline $\begin{array}{l}\text { Centratherum } \\
\text { anthelminticum ( } \\
\text { L.) }\end{array}$ & vernodalin & - & $\begin{array}{l}\text { MTT, Apoposis, } \\
\text { MMP }\end{array}$ & $\begin{array}{l}\text { Increased } \quad \text { caspase } \\
\text { expression }\end{array}$ \\
\hline Curcuma longa & curcumin & $\begin{array}{l}\text { High antioxidant } \\
\text { activity }\end{array}$ & $\begin{array}{l}\text { MTT, western } \\
\text { blot, } \\
\text { cytometry }\end{array}$ & $\begin{array}{l}\text { Induction of apoptosis } \\
\text { Reduced } \quad \mathrm{BCl}-2 \\
\text { expression/ increased } \\
\text { Bax expression }\end{array}$ \\
\hline $\begin{array}{l}\text { Nardostachys } \\
\text { jatamansi DC }\end{array}$ & - & $\begin{array}{l}\text { High antioxidant } \\
\text { activity }\end{array}$ & Cell cycle, MTT & $\begin{array}{l}\text { Enhanced cell cycle } \\
\text { arrest } \\
\text { Significant death of } \\
\text { cancer cells }\end{array}$ \\
\hline $\begin{array}{l}\text { Scrophularia } \\
\text { oxysepala }\end{array}$ & - & - & $\begin{array}{l}\text { MTT, Apoposis, } \\
\text { cell cycle }\end{array}$ & $\begin{array}{l}\text { Increased effector } \\
\text { caspase expression } \\
\text { Enhanced cell cycle } \\
\text { arrest }\end{array}$ \\
\hline Mikania cordata & - & & MTT & $\begin{array}{l}\text { Inhibited proliferation } \\
\text { of cells }\end{array}$ \\
\hline Piper cubeba & - & - & $\begin{array}{l}\text { DNA } \\
\text { fragmentation } \\
\text { assay }\end{array}$ & Induced apoptosis \\
\hline $\begin{array}{l}\text { Dysoxylum } \\
\text { binectariferum }\end{array}$ & flavopiridol & $\begin{array}{l}\text { Rich in phenols, } \\
\text { high antioxidant } \\
\text { activity }\end{array}$ & Metabolomics & $\begin{array}{l}\text { Cell cycle arrest } \\
\text { Induction of apoptosis } \\
\text { Alteration in redox }\end{array}$ \\
\hline
\end{tabular}




\begin{tabular}{|l|l|l|l|l|}
\hline $\begin{array}{l}\text { Solanum } \\
\text { lycopersicum }\end{array}$ & lycopene & $\begin{array}{l}\text { High antioxidant } \\
\text { activity }\end{array}$ & MTT, western blot & $\begin{array}{l}\text { Suppression of cyclin } \\
\text { D1 } \\
\text { Upregulation of p21 }\end{array}$ \\
\hline Vitis vinifera & resveratrol & $\begin{array}{l}\text { Rich in phenols, } \\
\text { high antioxidant } \\
\text { activity }\end{array}$ & $\begin{array}{l}\text { MTT, Enzyme } \\
\text { assays }\end{array}$ & $\begin{array}{l}\text { Reduced cell viability } \\
\text { Reduced } \\
\text { Phosphofructokinase } \\
\text { activity }\end{array}$ \\
\hline
\end{tabular}

Table 1: A summary of selected findings on the effect of phytochemicals on MCF-7 cells

Another emerging field of phytochemicals in breast cancer research is in their potential as adjuvants for conventional cancer treatments, due to their protective antioxidant role against oxidative stress and cellular alterations (side effects) associated with the use of conventional cancer treatment regimens [77]. In this regard, it is noteworthy that concerns have been raised with respect to antioxidant supplementation during breast cancer treatment, with some studies showing improved survival outcomes, ascribed to protection of normal cells by antioxidant phytochemicals from the pro-oxidant effects of radiation and chemotherapy, while other results show opposite effects [78]. This necessitates further studies to determine appropriate concentrations and particular phytochemicals to be used in a particular sub-type of breast cancer.

Results obtained from a study which examined post diagnosis vitamin c supplementation in breast cancer patients found reduced risk of total mortality and breast cancer-specific mortality [79]. Another study evaluated the potent growth inhibitory effects of aqueous wheatgrass extract in combination with cisplatin (a therapeutic drug with a reported number of side effects) at low concentration combination on MCF-7. The results showed decreased cell viability in the combination treatment compared to individual concentrations of cisplatin, and a combination index less than 1 indicating a synergistic action when combined at the concentrations used [80]. These observations and studies points out immense prospects for the development of therapeutic strategies using phytochemicals in combination with other treatment regimens, that could overcome side-effects currently observed among breast cancer patients treated by conventional therapies.

\section{CONCLUSION}


Many studies have examined the role of reactive oxygen species mediated oxidative stress in carcinogenesis, as well as the effect of synthetic and natural compounds in the inhibition of MCF-7 growth and proliferation. However, the growing trend of cancer incidence and mortality worldwide necessitates further in depth studies with respect to cancer prevention. Phytochemicals have great potential in this regard, due to associated side effects from currently used therapies and an observed trend towards the use of natural compounds in the treatment of disease, as against the use of synthetic compounds. Thus, there is a need to investigate the active constituents present in reported anti-cancer phytochemicals, elucidate the biochemical and molecular mechanisms responsible for any observed anti-cancer effects, correlate in vitro anticancer experiments with further in vivo studies and develop safer, readily available and cheaper, therapeutic compounds for use by breast cancer and breast cancer predisposed patients.

\section{ACKNOWLEDGEMENT}

This work was supported by funds from the National Research Foundation (NRF) and facilities at the University of Pretoria, South Africa.

\section{REFERENCES}

1. Jemal A, Bray F, Center MM, Ferlay J, Ward E, Forman D. Global cancer statistics. CA Cancer J Clin. 2011;61(2):69-90.

2. Ferlay J, Soerjomataram I, Ervik M, Dikshit R, Eser S. GLOBOCAN 2012 v1.0, cancer incidence and mortality worldwide. IARC Cancer Base No. 11, 2013. International Agency for Research on Cancer, Lyon, France

3. Schlebusch CM, Dreyer G, Sluiter MD, Yawitch TM, VandenBerg HJ, Van rensburg EJ. Cancer prevalence in 129 breast-ovarian cancer families tested for BRCA1 and BRCA2 Mutations. SAMJ 2010;100(2): 113-117

4. Jedy-Agba E, Curado MP., Ogunbiyi O, Oga E, Fabowale T, Igbinoba F. Osubor G, Otu T, Kumai H, Koechlin A, Osinubi P, Dakum P, Blattner W, Adebamowo CA. Cancer incidence in Nigeria: a report from population-based cancer registries. Cancer Epidemiol. 2012;36(5): 271-278

5. Ekwueme DU, Guy GP Jr, Rim SH, White A, Hall IJ, Fairley TL, Dean HD. Health and economic impact of breast cancer mortality in young women, 1970-2008. Am J Prev Med. 2014;46(1):71-9

6. Anderson KN, Schwab RB, Martinez ME. Reproductive Risk Factors and Breast Cancer Subtypes: A Review of the Literature. Breast Cancer Res Treat. 2014;144(1): 1-10

7. Russo J, Hu YF, Silva ID, Russo IH. Cancer risk related to mammary gland structure and development. Microsc Res Tech. 2001; 52(2):204-223

8. Forcados GE, Chinyere CN, Shu ML. Acalypha wilkesiana: Therapeutic and Toxic Potential. J Med Surg Pathol. 2016;1:3 
9. Alpay M, Backman LR, Cheng X, Dukel M, Kim WJ, Ai L, Brown KD. Oxidative stress shapes breast cancer phenotype through chronic activation of ATM-dependent signaling. Breast Cancer Res Treat. 2015;151(1):75-87

10. Pisoschi AM, Pop A. The role of antioxidants in the chemistry of oxidative stress: A review. Eur J Med Chem. 2015;5(97):55-74

11. Valko M, Leibfritz D, Moncol J, Cronin MTD, Mazura M, Telser J. Free radicals and antioxidants in normal physiological functions and human disease. The International Journal of Biochemistry \& Cell Biology. 2007;39: 44-84

12. Liou G, Storz P. Reactive oxygen species in cancer. Free Radic Res. 2010;44(5)

13. Roque AT, Gambeloni RZ, Felitti S, Ribeiro ML, Santos JC. Inflammation-induced oxidative stress in breast cancer patients. Med Oncol. 2015;32(12):263

14. Yadav N, Kumar S, Marlowe T, Chaudhary AK, Kumar R, Wang J, Malley JO, Boland PM, S Jayanthi S, Kumar TKS, Yadava N, Chandra D. Oxidative phosphorylationdependent regulation of cancer cell apoptosis in response to anticancer agents. Cell Death Dis. 2015; 6(11)

15. Hill MM, Adrain C, Duriez PJ, Creagh EM, Martin SJ. Analysis of the composition, assembly kinetics and activity of native Apaf-1 apoptosomes. Embo J. 2004;23:2134-45.

16. Stadtman ER. Role of oxidant species in aging. Curr. Med. Chem. 2004;11: 1105-1112.

17. Hohn A, Jung T, Grune T. Pathophysiological importance of aggregated damaged proteins. Free Radic Biol Med. 2014;71:70-89

18. Weber D, Davies MJ, Grune T. Determination of protein carbonyls in plasma, cell extracts, tissue homogenates, isolated proteins: Focus on sample preparation and derivatization conditions. Redox Biol. 2015;5: 367-380.

19. Schupp N, Schinzel R, Heidland A, Stopper H. Genotoxicity of advanced glycation end products: involvement of oxidative stress and of angiotensin II type 1 receptors. Ann N Y Acad Sci. 2005;1043:685-95.

20. Younessi P, Yoonessi A. Advanced Glycation End-Products and Their ReceptorMediated Roles: Inflammation and Oxidative Stress. Iran J Med Sci. 2011;36(3): 154166.

21. Matsui A, Ikeda T, Enomoto K, Hosoda K, Nakashima H, Omae K, Watanabe M, Hibi T, Kitajima M. Increased formation of oxidative DNA damage, 8-hydroxy-2'deoxyguanosine, in human breast cancer tissue and its relationship to GSTP1 and COMT genotypes. Cancer Lett. 2000;151:87-95

22. Sova H, Jukkola-Vuorinen A, Puistola U, Kauppila S, Karihtala P. 8-Hydroxydeoxy guanosine: a new potential independent prognostic factor in breast cancer. Br J Cancer. 2010;102(6): 1018-1023

23. Rivlin N, Brosh R, Oren M, Rotter V. Mutations in the p53 Tumor Suppressor Gene: Important Milestones at the Various Steps of Tumorigenesis. Genes Cancer. 2011;2(4): 466-47

24. Birben E, Sahiner UM, Sackesen C, Erzurum S, Kalayci O. Oxidative Stress and Antioxidant Defense. World Allergy Organ J. 2012;5(1): 9-19.

25. Jia J, Ye T, Cui P, Hua Q, Zeng H, Zhao D. AP-1 transcription factor mediates VEGFinduced endothelial cell migration and proliferation. Microvasc Res. 2016;105: 103-108.

26. Castaldo SA, Freitas JR, Conchinha NV, Madureira PA. The tumorigenic roles of the cellular REDOX regulatory systems. Oxid Med Cell Longev. 2015. doi: $10.1155 / 2016 / 8413032$ 
27. Kharman-Biz A, Gao H, Ghiasvand R, Zhao C, Zendehdel K, Dahlman-Wright K. Expression of activator protein-1 (AP-1) family members in breast cancer. BMC Cancer. 2013;13: 441.

28. Morgan MJ, Liu Z. Crosstalk of reactive oxygen species and NF- $\kappa$ B signaling. Cell Res. 2011 Jan; 2011;21(1): 103-115.

29. Su B, Karin M. Mitogen-activated protein kinase cascades and regulation of gene expression. Curr Opin Imm. 1996;8:402-11.

30. Zhou J, Ching YQ, Chn W. Aberrant nuclear factor-kappa B activity in acute myeloid Leukemia: from molecular pathogenesis to therapeutic target. Oncotarget. 2015;6(8): 5490-5500

31. Morgan MJ, Liu Z. Crosstalk of reactive oxygen species and NF- $\kappa B$ signaling. Cell Res. 2011;21(1): 103-115.

32. Benedetti S, Nuvoli B, Catalani S, Ga R. Reactive oxygen species a double-edged sword for mesothelioma. Oncotarget. 2015;6(19): 16848-16865

33. Shostak K, Chariot A. NF-кB, stem cells and breast cancer: the links get stronger. Breast Cancer Res. 2011;13(4): 214.

34. Connelly L, Barham W, Onishko HM, Sherrill T, Chodosh LA, Blackwell TS, Yull FE. Inhibition of NF-kappa B activity in mammary epithelium increases tumor latency and decreases tumor burden. Oncogene. 2011;30(12):1402-12

35. Zubair A, Frieri M. Role of nuclear factor-кB in breast and colorectal cancer. Curr Allergy Asthma Rep. 2013;13(1):44-9

36. Pflaum J, Schlosser S, Martina MM. p53 Family and Cellular Stress Responses in Cancer. Front Oncol. 2014;4: 285.

37. Goh AM, Xue Y, Leushacke M, Li L, Wong JS, Chiam PC, Rahmat SAB, Mann MB, Mann KM, Barker N, Lozano G, Terzian T, Lane DP. Mutant p53 accumulates in cycling and proliferating cells in the normal tissues of p53 R172H mutant mice. Oncotarget. 2015;6(20): 17968-1798

38. Reinhardt HC, Schumacher B. The p53 network: cellular and systemic DNA damage responses in aging and cancer. Trends Genet 2012;28(3):128

39. Vijayakumaran R, Tan KH, Miranda PJ, Haupt S, Haupt Y. Regulation of Mutant p53 Protein Expression. Front Oncol. 2015;5:284.

40. Muller PAJ, Vousden KH. Mutant p53 in Cancer: New Functions and Therapeutic Opportunities. Cancer Cell. 2014;25(3): 304-317

41. Boutros T, Chevet E, Metrakos P. Mitogen-Activated Protein (MAP) kinase/MAP kinase phosphatase regulation: roles in cell growth, death, and cancer," Pharmacological Reviews. 2008;60(3): 261-310

42. Ramos-Ninos M, Haegens A, Shukla A, Mossman B. Role of mitogen-activated protein kinases (MAPK) in cell injury and proliferation by environmental particulates. Mol and Cell. Bioch. 2002;234-235:111-18

43. Avivar-Valderas A, Salas E, Bobrovnikova-Marjon E, Diehl JA, Nagi C, Debnath J, Aguirre-Ghiso JA. PERK integrates autophagy and oxidative stress responses to promote survival during extracellular matrix detachment. Mol Cell Biol. 2011;31(17):3616-29.

44. Avivar-Valderas A, Wen HC, Aguirre-Ghiso JA. Stress signaling and the shaping of the mammary tissue in development and cancer. Oncogene. 2013;33(48): 5483-5490. 
45. Kame M, Shouma S, El-Merzebany M, Kilic G, Veenstra T, Saeed M, Wagih M, Diaz-Arrastia C, Patel D, Salama S. Effect of Tumour Necrosis Factor-Alpha on Estrogen Metabolic Pathways in Breast Cancer Cells. Journal of Cancer. 2012;3:310-321

46. Dupont S, Krust A, Gansmuller A, Dierich A, Chambon P, Mark M. Effect of single and compound knockouts of estrogen receptors alpha and beta on mouse reproductive phenotypes. Development. 2000;127:4277-91.

47. Platet N, Cathiard AM, Gleizes M, Garcia M. Estrogens and their receptors in breast cancer progression: a dual role in cancer proliferation and invasion. Critical Reviews in Oncology/Hematology 2004;51: 55-67

48. Mahalingaiah PK, Ponnusamy L, Singh KP. Chronic oxidative stress causes estrogenindependent aggressive phenotype, and epigenetic inactivation of estrogen receptor alpha in MCF-7 breast cancer cells. Breast Cancer Res Treat. 2015;153(1):41-56

49. Yip $\mathrm{CH}$, Rhodes A. Estrogen and progesterone receptors in breast cancer. Future Oncol. 2014;(14):2293-301

50. Zhao M, Ramaswamy B. Mechanisms and therapeutic advances in the management of endocrine-resistant breast cancer. World J Clin Oncol. 2014;5(3): 248-262.

51. Osborne CK, Schiff R. Mechanisms of endocrine resistance in breast cancer. Annu Rev Med. 2011;62:233-47.

52. Francken AB, Schouten PC, Bleiker EMA, Linn SC, Rutgers EJ. Breast cancer in women at high risk: The role of rapid genetic testing for BRCA1 and -2 mutations and the consequences for treatment strategies. The Breast. 2013;22(5: 561-568

53. Yi YW, Kang HJ, Bae I. BRCA1 and Oxidative Stress. Cancers (Basel). 2014;6(2): 771795

54. Ma Y, Fan S, Hu C, Meng Q, Fuqua SA, Pestell RG, Tomita YA, Rosen EM. BRCA1 regulates acetylation and ubiquitination of estrogen receptor-alpha. Mol Endocrinol. 2010;24(1):76-90.

55. Wang L, Di L. BRCA1 And Estrogen/Estrogen Receptor In Breast Cancer: Where They Interact? Int J Biol Sci. 2014;10(5): 566-575.

56. Yedjou CG, Izevbigie EB, Tchounwou PB. Vernonia amygdalina-Induced Growth Arrest and Apoptosis of Breast Cancer (MCF-7) Cells. Pharmacology \& Pharmacy. 2013;4:939

57. Kunnumakkara AB, Anand P, Aggarwal BB. Curcumin inhibits proliferation, invasion, angiogenesis and metastasis of different cancers through interaction with multiple cell signaling proteins. Cancer Letters. 2008;269(2): 199-225

58. Mikaili P, Mojaverrostami S, Moloudizargari M, Aghajanshakeri S. Pharmacological and therapeutic effects of Mentha Longifolia L. and its main constituent, menthol. Anc Sci Life. 2013;33(2): 131-138

59. Farombi EO, Shrotriya S, Na HK, Kim SH, Surh YJ. Curcumin attenuates dimethylnitrosamine-induced liver injury in rats through Nrf2-mediated induction of heme oxygenase-1. Food Chem Toxicol. 2008;46(4):1279-87

60. Lee AV, Oesterreich S, Davidson NE. MCF-7 cells--changing the course of breast cancer research and care for 45 years. J Natl Cancer Inst. 2015;107(7).

61. Mphahlele MJ, Maluleka MM, Makhafola TJ, Mabeta P. Novel polycarbo-substituted alkyl (thieno[3,2-c]quinoline)-2-carboxylates: synthesis and cytotoxicity studies. Molecules. 2014;19(11):18527-42 
62. Holliday DL, Speirs V. Choosing the right cell line for breast cancer research. Breast Cancer Res. 2011;13(4): 215

63. Comsa S, Cimpean AM, Raica M. The Story of MCF-7 Breast Cancer Cell Line: 40 years of Experience in Research. Anticancer Res. 2015;35(6):3147-54.

64. Burdall SE, Hanby AM, Lansdown MRJ, Speirs V. Breast cancer cell lines: friend or foe? Breast Cancer Res. 2003;5(2): 89-95.

65. Johnston SJ, Cheung KL. Fulvestrant - a novel endocrine therapy for breast cancer. Curr Med Chem. 2010;17(10):902-14

66. Graidist P, Martla M, Sukpondma Y. Cytotoxic Activity of Piper cubeba Extract in Breast Cancer Cell Lines. Nutrients. 2015;7:2707-2718

67. Uy TGC, Licuanan AM, Angeles GED, Bote MLCC, Macauyag EAB, Hernandez CC, Jacinto SD, Guzman-Genuino RM. Anti-cancer effect and mechanism of action of Mikania cordata plant extract on MCF-7 Human breast adenocarcinoma cells. International Journal of cancer research. 2015;11(2): 80-92

68. Chaudhary S, Chandrashekar KS, Pai KSR, Setty MM, Devkar RA, Reddy ND, Shoja MH. Evaluation of antioxidant and anticancer activity of extract and fractions of Nardostachys jatamansi DC in breast carcinoma. BMC Complementary and Alternative Medicine. 2015;15:50

69. Looi CY, Arya A, Cheah FK, Muharram B, Leong KH, Mohamad K, Wong WF, Rai N, Mohd Mustafa R. Induction of Apoptosis in Human Breast Cancer Cells via Caspase Pathway by Vernodalin Isolated from Centratherum anthelminticum (L.) Seeds. PLoS One. 2013;8(2): e56643.

70. Hosseini B, Pasdaran A, Kazemi T, Shanehbandi D, Karami H, Orangi M, Baradaran B. Dichloromethane fractions of Scrophularia oxysepala extract induce apoptosis in MCF-7 human breast cancer cells. Bosn J Basic Med Sci. 2015;15(1): 26-32.

71. Lv Z, Liu X, Zhao W, Dong Q, Li F, Wang H, Kong B. Curcumin induces apoptosis in breast cancer cells and inhibits tumor growth in vitro and in vivo. Int J Clin Exp Pathol. 2014;7(6):2818-2824

72. Pan L, Chai H, Kinghorn AD. Discovery of new anticancer agents from higher plants. Front Biosci (Schol Ed). 2012;4:142-156.

73. Shao X, Gao D, Wang Y, Jin F, Wu Q, Liu H. Application of metabolomics to investigate the antitumor mechanism of flavopiridol in MCF-7 breast cancer cells. J Chromatogr B Analyt Technol Biomed Life Sci. 2016;1025:40-47

74. Takeshima M, Ono M, Higuchi T, Chen C, Hara T, Nakano S. Anti-proliferative and apoptosis-inducing activity of lycopene against three subtypes of human breast cancer cell lines. Cancer Sci. 2014;105(3):252-7

75. Gomez LS, Zancan P, Marcondes MC, Ramos-Santos L, Meyer-Fernandes JR, SolaPenna M, Da Silva D. Resveratrol decreases breast cancer cell viability and glucose metabolism by inhibiting 6-phosphofructo-1-kinase. Biochimie. 2013;95(6):1336-43

76. Zancan P, Sola-Penna M, Furtado CM, Da Silva D. Differential expression of phosphofructokinase-1 isoforms correlates with the glycolytic efficiency of breast cancer cells. Mol. Genet. Metab. 2010;100:372-378

77. Farzaei MH, Bahramsoltani R, Rahimi R. Phytochemicals as adjunctive with conventional anticancer therapies. Curr Pharm Des. 2016 May 31. PMID: 27262332 
78. Greenlee H, Kwan ML, Kushi LH, Song J, Castillo A, Weltzien E, Quesenberry CP Jnr, Caan BJ. Antioxidant supplement use after breast cancer diagnosis and mortality in the LACE Cohort. Cancer. 2012;118(8): 2048-2058.

79. Harris HR, Orsini N, Wolk A. Vitamin C and survival among women with breast cancer: a meta-analysis. Eur J Cancer. 2014;50(7):1223-31

80. Hussain A, Gheewala TM, Vas AJ, Shah K, Goala P, Khan S, Hinduja S, Sharma C. (2014). Growth inhibitory and adjuvant therapeutic potential of aqueous extract of Triticum aestivum on MCF-7 and HeLa cells. Exp Oncol. 2014;36(1):9-16. 